\title{
Analysis of Extended Hollo-Bolt Connections: Combined Failure in Tension
}

\author{
Manuela Cabrera ${ }^{a *}$, Walid Tizani ${ }^{a}$, Mohammed Mahmood ${ }^{b}$, Mohd F. Shamsudin ${ }^{a, c}$. \\ ${ }^{a}$ Centre for Structural Engineering and Informatics (CSEI), University of Nottingham, NG7 2RD, United Kingdom. \\ ${ }^{b}$ Department of Civil Engineering, University of Diyala, Diyala, Iraq. \\ ${ }^{c}$ Department of Civil Engineering, University of Malaya, Malaysia.
}

\section{ARTICLE I N F O}

\section{Keywords:}

Blind bolt connections

Extended Hollo-Bolt

Combined failure

Tension

Numerical modelling

Analytical modelling

\section{A B S T R A C T}

This paper investigates the combined failure mode of the Extended Hollo-Bolt (EHB) and the effect of the column thickness on the tensile behaviour of the blind fastener. A three-dimensional Finite Element (FE) model was developed, validated against experimental data and used in a parametric study. The non-linear numerical model, which simulates a single row of two EHB in tension, presents reliable results of the column and bolt failure modes in agreement with experimental data. It is concluded that the failure mode is first controlled by the plastic resistance of the component limited by concrete crushing and hollow section yielding; it is then controlled by the strength of the bolt. An analytical model which predicts the global force-displacement relationships when varying the column thickness is proposed. Therefore, the stiffness and the strength behaviours of this combined mode of failure for the studied blind fastener can be estimated.

\section{Introduction}

Blind-bolted systems are a relatively new approach to connect open and hollow steel structural members, which are structurally more efficient compression members than open sections [1,2]. These systems only require access to one side of the hollow section to tighten the bolt [3]. According to Mirza \& Uy [4], when blind-bolted systems are combined with concrete filled sections, beneficial behaviour is achieved due the bond and bearing action produced in the interaction and also because the infill concrete reduces the column face flexibility and deformations while the strength and stiffness of the tube walls are increased $[5,6,7]$.

From the available blind-bolts, including Hollo-bolt (Lindapter International, UK), Molabolt (Advanced Bolting Solutions, UK), Huck Bolt (Huck International, USA), Flowdrill (Flowdrill B.V., The Netherlands), and Ajax Oneside (Ajax Engineered Fasteners, Australia), modifications have been made to improve their momentresisting capacity in steel connections [8]. The Extended Hollo-Bolt (EHB) (Fig. 1) is a modification of the commercial Lindapter Hollo-Bolt (HB) developed at The University of Nottingham UK by Tizani \& Ridley-Ellis [9]. An additional anchor nut is attached to the end of an extended bolt shank to benefit from the concrete infill, which significantly increases the stiffness of the blind bolt system [10].

The use of this blind-bolted connector in joints constitutes an attractive construction technique due to the EHB potential performance in moment-resisting joints $[11,12]$.

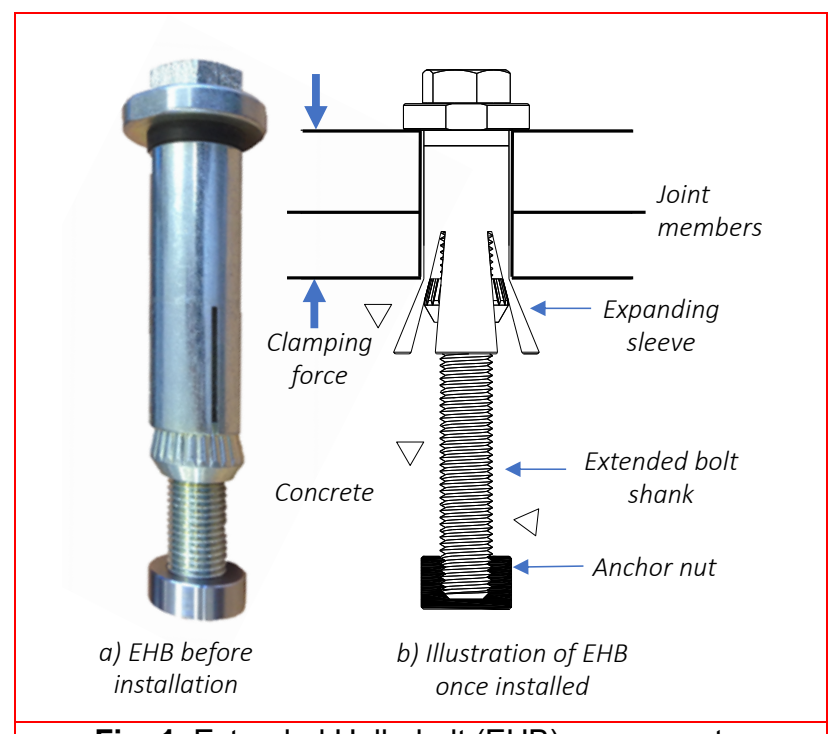

Fig. 1. Extended Hollo-bolt (EHB) components.

\footnotetext{
* Corresponding author at: University of Nottingham, NG7 2RD, Nottingham, United Kingdom.

E-mail address: manuelacrdr@gmail.com (M, Cabrera)
} 
2

\section{Notation}

$d \mathrm{~b} \quad$ Bolt diameter

dc Compression damage parameter

$d_{\text {emb }}$ Embedded depth

$E_{c m}$ Concrete Young's modulus

$E_{s} \quad$ Steel Young's modulus

$f_{c m}$ Concrete compressive strength

$F_{d} \quad$ Lowest strength of the combined failure component after the plastic load

$F_{p} \quad$ Plastic strength of the combined failure component

$F_{R} \quad$ Component resistance

$F_{u} \quad$ Ultimate strength

$G_{f} \quad$ Fracture energy

$G_{f o}$ Base fracture energy

$k_{i} \quad$ Initial stiffness of the combined failure component

$k_{d} \quad$ Drop stiffness of the combined failure component

$k_{s} \quad$ Secondary stiffness of the combined failure component

$k_{u} \quad$ Final stiffness of the combined failure component

$\varepsilon_{c} \quad$ Compressive strain of concrete

$\varepsilon^{p l} l_{c} \quad$ Concrete compressive plastic strain

$\Delta_{i} \quad$ Displacement at $0.75 F_{p}$

$\Delta_{p} \quad$ Displacement at $F_{p}$

$\Delta_{d} \quad$ Displacement at $F_{d}$

$\Delta_{u} \quad$ Displacement at $F_{u}$

$\psi \quad$ Dilation angle for CDP

$\delta_{c} \quad$ Deformation capacity

$\mu \quad$ Slenderness ratio for the column face

Pitrakkos et al. [13] and Pitrakkos \& Tizani [6] identified three potential failure modes for EHB connections which are bolt failure, column face failure and combined failure. Independent experimental and numerical studies have been carried out to investigate the first two failure modes separately.

For the bolt component, Pitrakkos et al. [13] evaluated bond and anchorage mechanisms by means of an experimental programme where different bolt diameters, concrete strengths, bonded lengths, shank lengths, shank grades and embedment depths were considered. The tensile behaviour of the EHB bolt component was evaluated by Tizani \& Pitrakkos [14] where the type of fastener, addition of concrete to the tube, strength of the concrete, spacing between bolts, and bolt class were the main test variables. Pitrakkos \& Tizani [6] investigated the strength, stiffness and ductility of single EHB bolt component by conducting monotonic tensile pull-out, bolt pre-load and relevant material property testing. The cyclic behaviour of the EHB was evaluated by Tizani et al. [11] by means of quasi-static cyclic loading tests.

For the column face component, Mahmood et al. [15] studied the column face thickness effect on the bending behaviour of a single row EHB connections by using experimental and numerical methods. The bolt gauge distance effect on the bending behaviour of the column face component was evaluated by Mahmood et al. [12] who carried out experimental and numerical studies on EHB connections.

In general, previous research has demonstrated that the tensile stiffness of the EHB exceeds that of the HB, and that the joint when using this blind bolt can develop moment resistance sufficient for it to be classified as rigid, depending on the geometry of the connection and the connecting structural members and its behaviour is adequate due to its energy dissipation capacity and ductility. Besides, analytical models based on the component method were proposed for both components (bolt in tension and column face in bending) achieving good accuracy compared with experimental data. However, the combined failure has not been investigated yet.

This work devises a Finite Element (FE) model to simulate the behaviour of the EHB under tension when a combined failure can occur. It validates the model against experimental data reported from independent research done for the bolt and column face components. Parametric studies are carried out by varying the column face thickness. The analyses are performed for a row of two EHB with bolt diameter $16 \mathrm{~mm}$, bolt shank length $150 \mathrm{~mm}$, bolt grade 8.8 , concrete strength $40 \mathrm{MPa}$ and variable column thickness. An analytical model is formulated using the output from the parametric studies and cross-checked for conformance with the experimental data and the numerical model.

This paper will first introduce the experimental programme followed by the numerical model assumptions and validation and finally how the analytical model was arrived at. It concludes with the analytical model validation.

\section{Experimental programme review}

The experimental programme includes a review of previous monotonic tensile pull-out, bolt pre-load, and material property tests in order to evaluate the load transfer mechanisms of the EHB components, determine the full force-displacement response and investigate the effect of different parameters on the behaviour of the connection.

\subsection{Bolt Component}

\subsubsection{Monotonic tensile pull-out tests}

Pitrakkos [16] carried out 16 EHB pull-out tests varying the bolt diameter, $d_{b}(16 \& 20 \mathrm{~mm})$; the grade of the bolts (8.8 \& 10.9); the concrete infill strength (C40 \& C60); and the embedded depth, $d_{e m b}\left(4.0-6.5 d_{b}\right)$. The setup involves a reusable steel box assembly with a rigid top plate $(20 \mathrm{~mm}$ thick) which simulates a relatively rigid rectangular hollow section, two hollow section frames which act as the reaction forces, a circular loading plate (25mm thick), a concrete infill and the EHB specimen. The monotonic tensile pull-out test setup is shown in Fig. 2.

\subsection{2 bolt pre-load tests}

20 pre-load measurements were performed. Readings 
were taken during and after tightening of the bolts allowing for the relaxation effect. The initial pre-load reading was taken once the tightening torque was

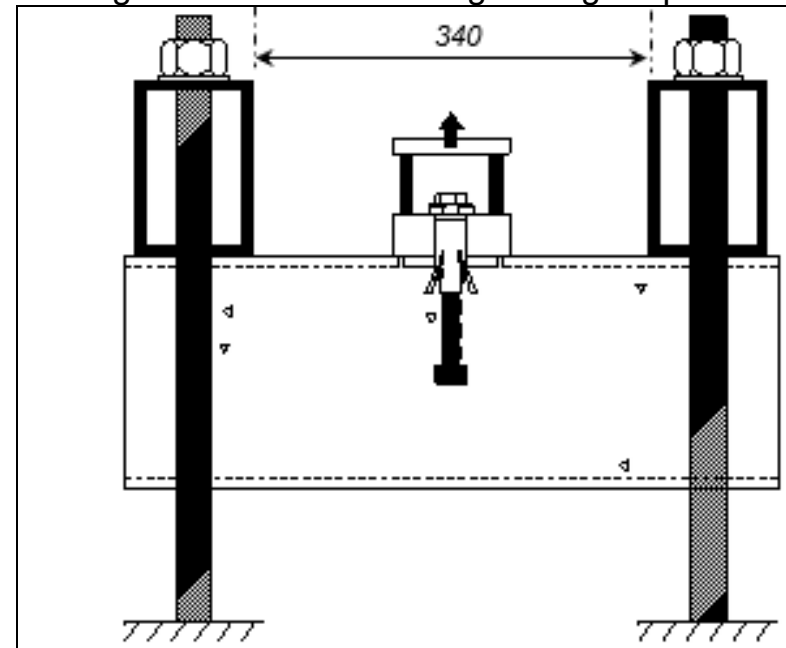

a) Test rig for bolt pull-out

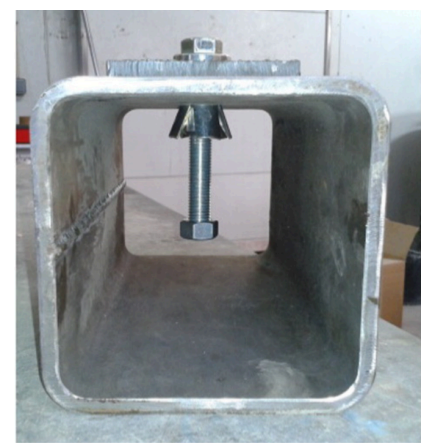

b) Illustration of installed EHB before concrete infill

Fig. 2. Bolt component pull-out test setup [6].

achieved and the residual pre-load reading was taken after 5 days of tightening.

\subsection{Column Face Component}

Mahmood et al. [15] carried out 39 EHB pull-out tests varying the hollow section plate thickness or slenderness ratio $\mu=b / t(25,31.75 \& 40 \mu)$; the concrete grade (C20, C40 \& C90); the bolt gauge $g(80,140 \& 180 \mathrm{~g})$; the bolt pitch $p(120,200,280 p)$; the anchorage length $L_{a n}(80$, $103 \& 112 \mathrm{~mm})$; and the concrete type. The setup involves reusable dummy bolts (DB) which have a simplified geometry for the sleeves (Fig. 3) and are manufactured from high strength steel (EN24 steel) which ensures pure face bending behaviour and eliminates the bolt failure mechanism. The test rig provides support for the specimens against the applied load. The test arrangement is illustrated in Fig. 4.

An Imetrum's Video Gauge (VG) system and a Digital Image Correlation Q-400 (DIC) system (Dantec) were used to record the column face displacement, the EHB slip, the sample movement and the strain distribution at the column face.

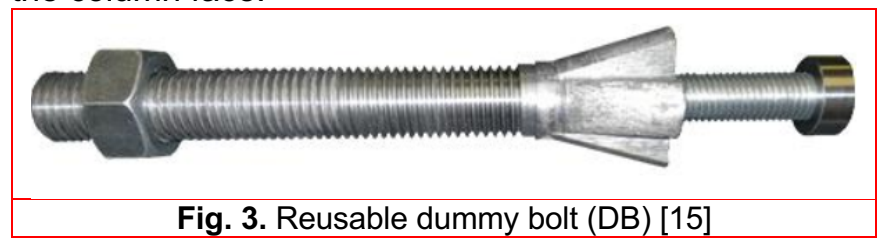

\subsection{Measured material properties}

For both components, a series of pull-out tests were performed in accordance with ISO 898-1:2009 (BSI 2009) on the bolt batches used throughout the experimental programmes. They were performed on machined and full-size bolts where the stress-strain relationships were obtained. The concrete mixes used nominal maximum aggregate size of $10 \mathrm{~mm}$. The concrete compressive strength of the specimens was tested using $100 \mathrm{~mm}$ cubes on the day of the testing and after 28-day of casting. The steel hollow section reaction frame and the $20 \mathrm{~mm}$ thick top plate are grade S355 and standard steel dog-bone tests were performed on the test pieces to determine the full force-displacement response. The test pieces were designed and tested according to Annex D of BS EN 100021:2001 (BSI 2001).

\section{Numerical model}

Three full-scale 3D models were built using the nonlinear FE software package Abaqus (version 6.15) which has high non-linear capabilities to accurately evaluate the behaviour of the component and provide stress magnitudes for the full loading range. The bolt failure is simulated according to Pitrakkos \& Tizani [6] and bending behaviour of the column face component according to Mahmood et al. [15] experimental data. The two validated models are assembled to evaluate the behaviour of the combined failure mode and the stiffness of the EHB connection in tension with a rigid plate when different column thicknesses are used. 


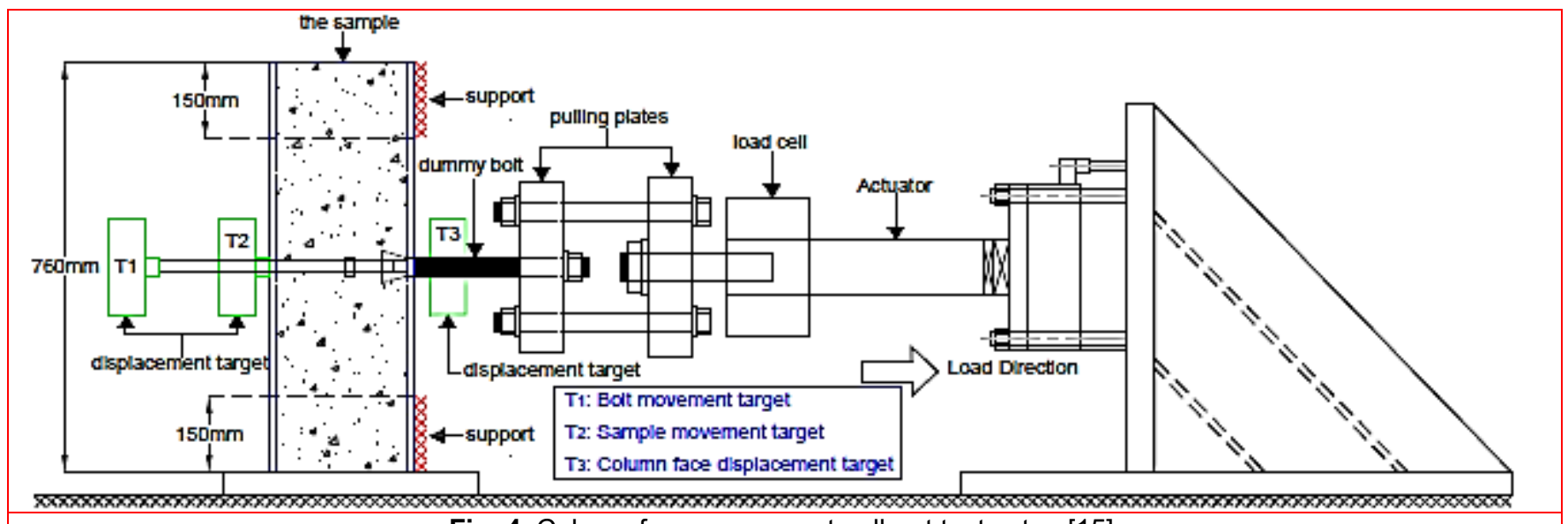

Fig. 4. Column face component pull-out test setup [15].

\subsection{Geometry}

The geometrical model for complex elements was built using AutoCAD 3D 2018 and exported to Abaqus as ".sat" files; graphical tools in Abaqus/CAE were used for simpler geometries. For the column component, the components of the bolt were modelled according to the real bolt instead of the dimensions of the dummy bolt used by Mahmood et al. [15] in order to allow comparisons between the two failure modes and consistency when combining the two models.

The dimensions of the deformed EHB after tightening were input in the model with exact dimensions as reported by Pitrakkos et al. [13] experimental tests. For the steel box, the plate thickness at the corners $\left(t_{c}\right)$ is slightly larger than the thickness of hollow section wall $(t)$ (see Fig. 5). Therefore, $R_{i}$ is taken as $\mathrm{t}$ and $R_{e}$ equal to $1.65 t$ in the model. This is so to model the actual dimensions of the manufactured tubes, which tend to have such dimensions due to hot-rolling.

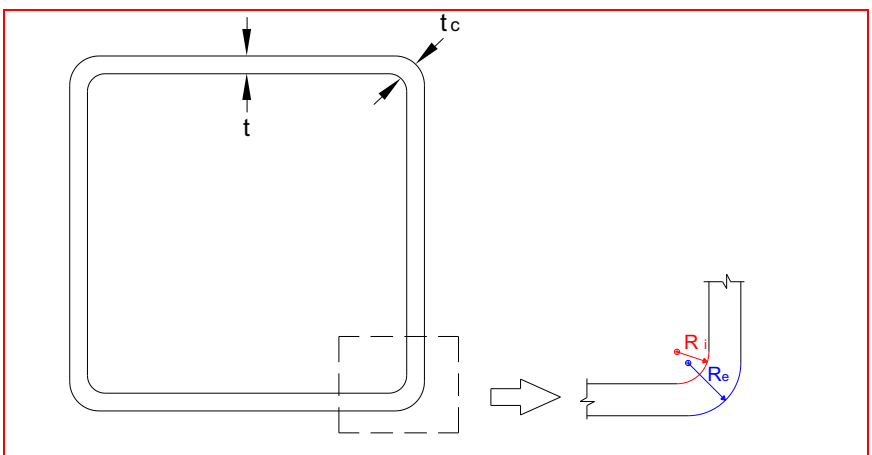

Fig. 5. Cross section and corner details for hollow section.

Only a quarter of the connection was modelled taking advantage of the symmetry in geometry, loads and constraints along the longitudinal and transverse axes.

\subsection{Meshing}

The discretization of the domain of each element is done using Abaqus cell partitioning tool which divides each element into pieces of simpler geometry which are less complex to be analysed by the software. The accuracy of the results and the processing time depend on the element size and discretization method. In order to optimise the model and obtain accurate results in the areas of interest, fine mesh was assigned to sections close to the EHB while coarse mesh to other regions which require less attention. To model the complex nonlinear behaviour, involving contact and geometrical nonlinearities of the connection, first order interpolation elements (C3D8) with full integration were used to model the hollow section and concrete. The circular geometry of the EHB inner part was meshed using a linear continuum 3D element with 6 nodes (C3D6). A mesh convergence was performed by simulating the same model with different element sizes. The mesh is considered as converged if the reduction in the element size causes a negligible difference in the resultant displacements and stresses. Since the precision of the plastic load results in the model is increased by $0.1 \%$ when very fine mesh (less than $10 \mathrm{~mm}$ ) is used for the bolt and the concrete and column elements around it, it is concluded that there is no need to use very fine mesh in the model. The thickness of the column was modelled using one to three mesh elements with no significant difference (less than $1 \%)$ in the stress and displacement results. The model with one element for thickness was therefore adopted for computing efficiency.

\section{3 Contacts}

Contact simulation in Abaqus prevents elements merging or penetrating and generates contact forces between them. Interaction constraints demarcate the limits of two regions in contact by normal or tangential load transfer between elements. While the elements are not in contact, no load transfer occurs. Surface-based contacts were defined in the model using the contact pair algorithm, in which the user needs to define the contact properties and link the related surfaces manually by 
specifying the "master" and the "slave" surfaces. The master surface is chosen to be the stiffest or the surface of the moving element in cases of similar stiffness. Normal and tangential behaviour models were used to define the interaction between two surfaces. In the first one, only the surfaces need to be defined and the software creates the link between them automatically. In the second model, it is required to define a friction modulus as a penalty friction behaviour for sliding. The friction modulus between concrete-steel contact is defined as 0.25, after Elremaily \& Azizinamini [18], Hu et al. [19] and Ellobody et al. [20]; and 0.45 after Wang [21] for steel-steel interaction.

\subsection{Material properties}

\subsubsection{Concrete}

Concrete behaviour is defined in Abaqus by introducing its elastic and plastic properties. The concrete compression behaviour was simulated assuming a linear elastic behaviour up to $40 \%$ of the ultimate concrete compressive strength. This part of the curve is defined by the concrete Young's modulus $\left(E_{c}\right)$ and the Poisson's ratio $(U) . E_{c}$ was calculated using the Eurocode model and $u$ was taken equal to 0.2. After the elastic range, a non-linear ascending curve starts until the ultimate concrete strength $\left(f_{\mathrm{cm}}\right)$ is reached, followed by a reduction in the concrete resistance.

The plastic behaviour is more complex to simulate due to the brittle nature of the material and since irreversible strains cannot be captured in elastic damage models. Concrete Damage Plasticity (CDP) can model concrete by assuming two main failure mechanisms, tensile cracking and compressive crushing. The nonlinear stress-strain curve is defined in the software by the plastic stresses and inelastic strain, plasticity parameters and the damage parameters.

The non-linear stress-strain curve was predicted by the model of BS EN1992-1-1. The plasticity parameters are $\psi$, dilation angle; $\varepsilon$, flow potential eccentricity; $\sigma_{b} \sigma_{c o}$, ratio of initial equibiaxial compressive yield stress to initial uniaxial compressive yield stress; $k_{c}$, yield shape parameter; and $\mu_{o}$, viscosity parameter.

A sensitivity check was performed to investigate the effect of $\psi$ on the behaviour of the concrete. It was found that $\psi$ has a significant impact on the component behaviour, especially after the plastic load. A dilation angle of $55^{\circ}$ was found to be suitable for the model. According to Genikomsou \& Polak [22], $K_{c}$ should take values between $2 / 3$, corresponding to the Rankine formulation, and 1, which corresponds to the DruckerPrager criterion. Referring to Abaqus [23], the value of $K_{c}$ should be in the range of 0.5 to 1 . Larger values of $K_{c}$ correspond to a stiffer behaviour as more elastic energy can be dissipated. After a sensitivity check, the value used for the models corresponds to 0.8 . The remaining plasticity parameters were taken as the default values specified in the Abaqus manual [23] and these values are 1.16 for $\sigma_{\mathrm{b}} / \sigma_{\mathrm{co}}$ and 0 for $\mu_{\mathrm{o}}$.

The compression damage parameter $\left(d_{c}\right)$ defines the softening branch of the stress-strain curve of the material characterized by the degradation in the elastic stiffness of the concrete. This parameter can take values between 0 and 1 where zero corresponds to undamaged material while one represents the total loss of strength [23]. The compression damage parameters are found using Eq. (1) [23] and it is dependent on the compression plastic strain $\varepsilon^{p l}{ }_{c}$ which is found from the laboratory.

$$
d_{c}=1-\frac{f_{c m}}{E_{c m}\left(\varepsilon_{c}-\varepsilon^{p l}\right)}
$$

An iterative method was used to find the maximum damage parameter. For the studied case, a maximum value of 0.55 was found as a suitable value and used in the FE models.

In tension, concrete behaviour was simulated using a bilinear model according to equations defined in CEN [24]. The results from the model were strongly influenced by the mesh size when large mass of concrete without reinforcement is modelled. In order to avoid this issue, an energy approach, introduced by Hillerborg [25], is used where the concrete brittle behaviour is defined by introducing the amount of energy required to open a unit area of crack calculated using Eq. (2) [22].

$$
G_{f}=G_{f 0}\left(\frac{f_{c m}}{10}\right)^{0.7}
$$

\subsubsection{Steel}

All the elements of the EHB were modelled using the elastic and the default plastic models in Abaqus. The yield strength $\left(f_{y}\right)$ of $406 \mathrm{MPa}$, ultimate strength $\left(f_{u}\right)$ of 537 $\mathrm{MPa}$ and the Young's modulus of elasticity $\left(E_{s}\right)$ of 207000 $\mathrm{MPa}$ for the hollow section were obtained by Pitrakkos \& Tizani [6] from coupon tensile tests according to EN 10002-1:2001 (BSI, 2001).

The stress-strain experimental results obtained by Pitrakkos \& Tizani [6] for the bolt shank were used for all the components of the EHB as no experiments were carried out for the remaining components. The EHB steel properties were defined using the default elastic and plastic models in Abaqus which require the definition of the Young's modulus $\left(E_{s}\right)$, Poisson's ratio $(v)$ and plastic strain and stress values.

\subsection{Loading}

\subsubsection{Bolt preload}

The bolt preload is applied in the model using Abaqus bolt-load which simulates tightening forces or length adjustments in bolts or fasteners [23] following these steps: 
6

1. Before the application of the preload, a very small displacement which has a negligible effect on the behaviour of the model was assigned as a boundary condition to the bolt. This guarantees that all the contacts between the elements are defined and activated.

2. The preload is a function of tightening torque and bolt diameter and was assigned using the specified torque for a M16 bolt. The preload is applied in Abaqus as a "bolt load" with magnitude of $11.5 \mathrm{kN}$, which is the preload measured after the specified torque was applied and relaxation has taken place, as reported by Pitrakkos [16]. It was assigned on two parallel surfaces of a partition located at the middle distance between the bolt head and the threaded cone.

3. The bolt was fixed at its current length to allow the bolt length to remain unchanged so that the force in the bolt can change according to the response of the model. This step is required as Abaqus cannot deactivate the bolt load.

\subsubsection{Pull-out load}

A displacement control pull-out model of $20 \mathrm{~mm}$ was applied at the bolt head to simulate the tensile load. This corresponds to be the maximum global displacement reported by Mahmood et al. [15] and it is bigger than the $7 \mathrm{~mm}$ reported by Pitrakkos \& Tizani [6]. This way, both mechanisms can be covered. The displacement was assigned as a boundary condition where the movements in all directions except the direction of the load were restrained.

\section{Numerical model verification and validation}

The reliability of the FE models is validated by comparing the component behaviour during the analysis, stiffness and strain distribution against experimental results. The FE models must display specific phenomena depending on the studied failure mode to be able to represent the experimental behaviour of the connection. For the bolt failure, concrete crushing above the anchor nut, bolt necking and concrete cone formation in tension must be displayed; for the column face failure, the yielding of the steel plate around the bolt holes and crushing of the concrete above the anchor nut must be presented. The validation involves verification of the general behaviour of the column face and bolt components, plastic load, initial stiffness and agreement between the force-displacement curves from experimental data and the FE models.

\subsection{Single EHB Component}

The single EHB component was simulated here as a quarter of the bolt placed at the centre of the specimen taking advantage of symmetry.

\subsubsection{General behaviour}

The general behaviour of the connection is well described by the model. Some important characteristics are that there were no penetrations between the model elements, the stress distribution is similar to the experimental results and high concertation of stresses was observed at the interacting surfaces between the elements. The failure mode corresponds to the complete bolt necking at the location where the pre-tightening force is applied. Similar to the experimental results reported by Pitrakkos [16], this occurs when the global displacement is $7 \mathrm{~mm}$ approximately. Stress distribution in the bolt is presented in Fig. 6.

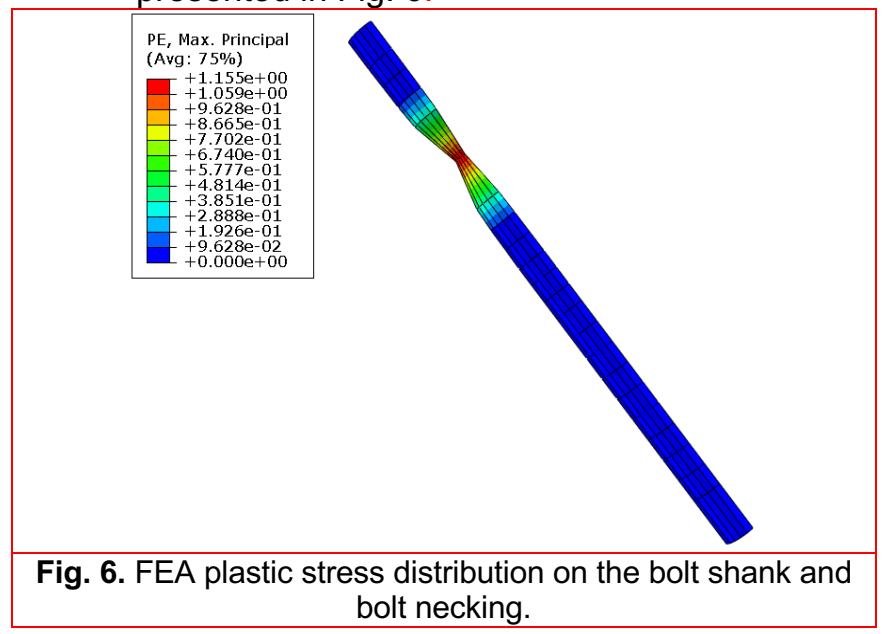

The model also displays concrete crushing above the anchor nut as the maximum concrete compressive strength is exceeded. In agreement with experimental data, the failure mode involves a concrete cone breakout of diameter $175 \mathrm{~mm}$, which forms at an approximate angle of $45^{\circ}$ to the horizontal as shown in Fig. 7.

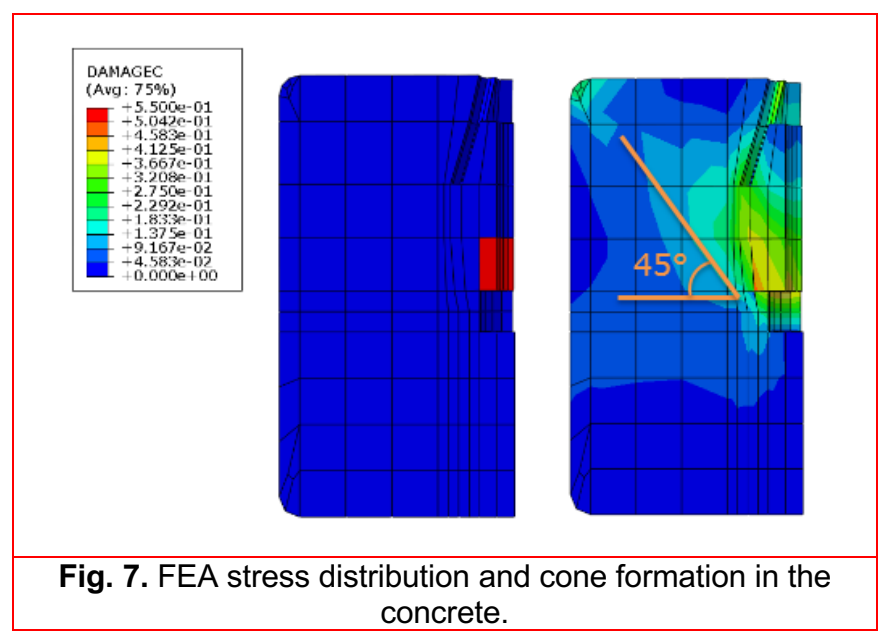

The top plate was assumed to be rigid and only elastic properties were assigned. Therefore, stresses resulted from the pull-out would not exceed its yield stress. This 
assumption was validated in the FE model by monitoring the stress variation along the thickness of the column plate. Since the variation is small enough to be neglected, it is proved that the component is rigid.

\subsubsection{Force vs displacement curves}

Comparison between the FE model and experimental results are displayed in Fig. 8. The model can represent the component stiffness, strength and the ductility within a $90 \%$ prediction band. The connection performance is controlled by the bolt ultimate tensile strength in agreement with the literature. Table 1 shows the experimental and numerical stiffness for the specimen EHB16-150-8.8D-C40*.

*Specimen index: (1)-(2)-(3)-(4), where:

(1) type of fastener (EHB) \& bolt shank diameter; (2) bolt shank length; (3) bolt shank grade \& designation of bolt batch and (4) grade of concrete infill.

Table 1

Numerical and experimental initial and second stiffness.

\begin{tabular}{lcccc}
$\begin{array}{c}\text { Force } \\
\text { interval }\end{array}$ & Stiffness & $\begin{array}{c}\text { Exp. } \\
(\mathbf{k N / m m})\end{array}$ & $\begin{array}{c}\text { Num. } \\
(\mathbf{k N / m m})\end{array}$ & $\begin{array}{c}\text { Error } \\
\mathbf{( \% )}\end{array}$ \\
\hline $0-0.25 \mathrm{~F}_{\mathrm{u}}$ & $\mathrm{k}_{1}$ & 781.84 & 825.19 & 5.5 \\
$0.25-0.9 \mathrm{~F}_{\mathrm{u}}$ & $\mathrm{k}_{2}$ & 192.58 & 210.54 & 9.3 \\
\hline
\end{tabular}

\subsection{EHB Bolt row Component}

In this section the behaviour of single row of two EHBs is investigated to evaluate the effect of group action on the failure mechanisms. It is assumed that the strength of the connection of two bolts is double of that obtained from one bolt. This assumption is true only if the failure mechanism is bolt necking, whereas when overlapping in the concrete cones exists a reduction in the component strength is expected. The whole specimen was modelled here to obtain clear understanding of the overlapping between the two bolts. Load - displacement curve obtained from the FE model is presented in Fig. 9 and compared to twice of the experimental resistance of single bolt.

The connection behaviour is described by the model within a $90 \%$ prediction band until around $6 \mathrm{~mm}$ of displacement. The failure mechanism corresponds to the necking of the bolts and these are the only components displaying plastic strains. Hence, the strength assumption is considered valid and the model verified.

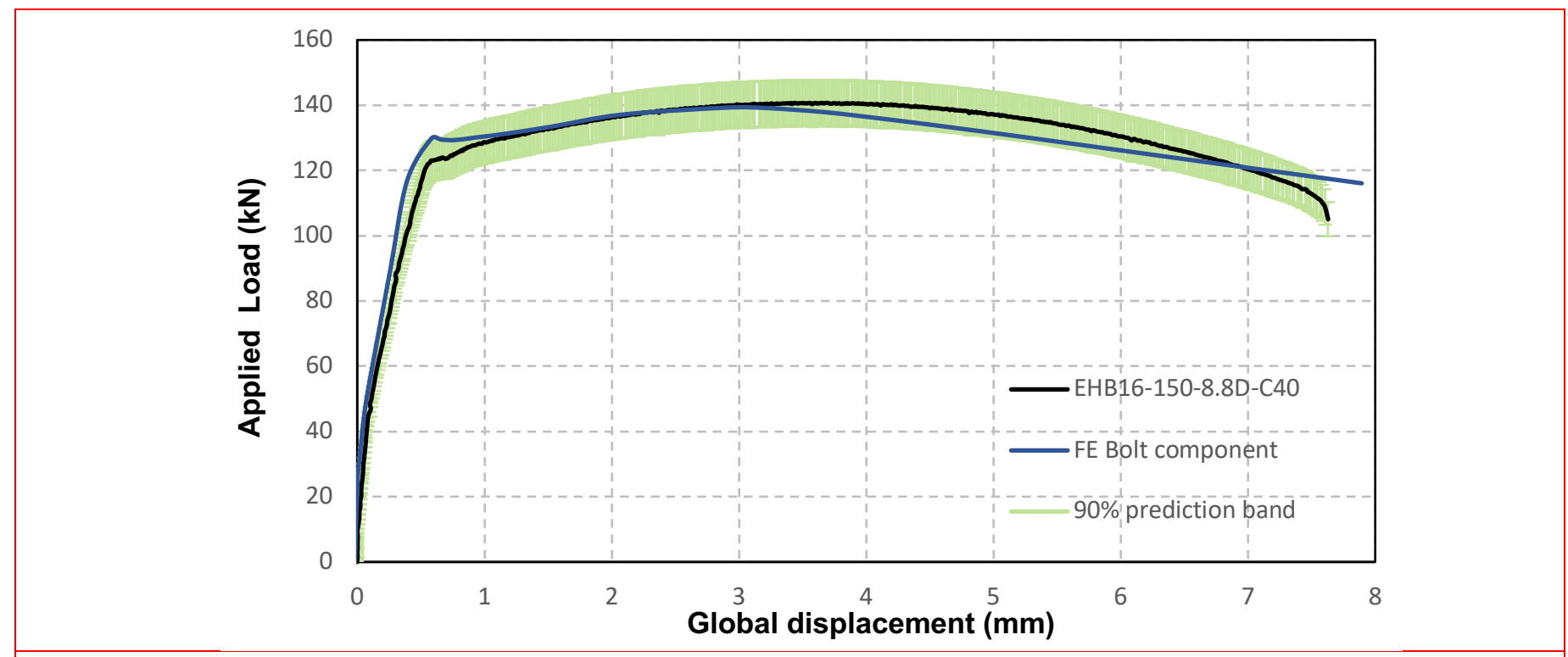

Fig. 8. Comparison of FEA model predictions with experimental data. 


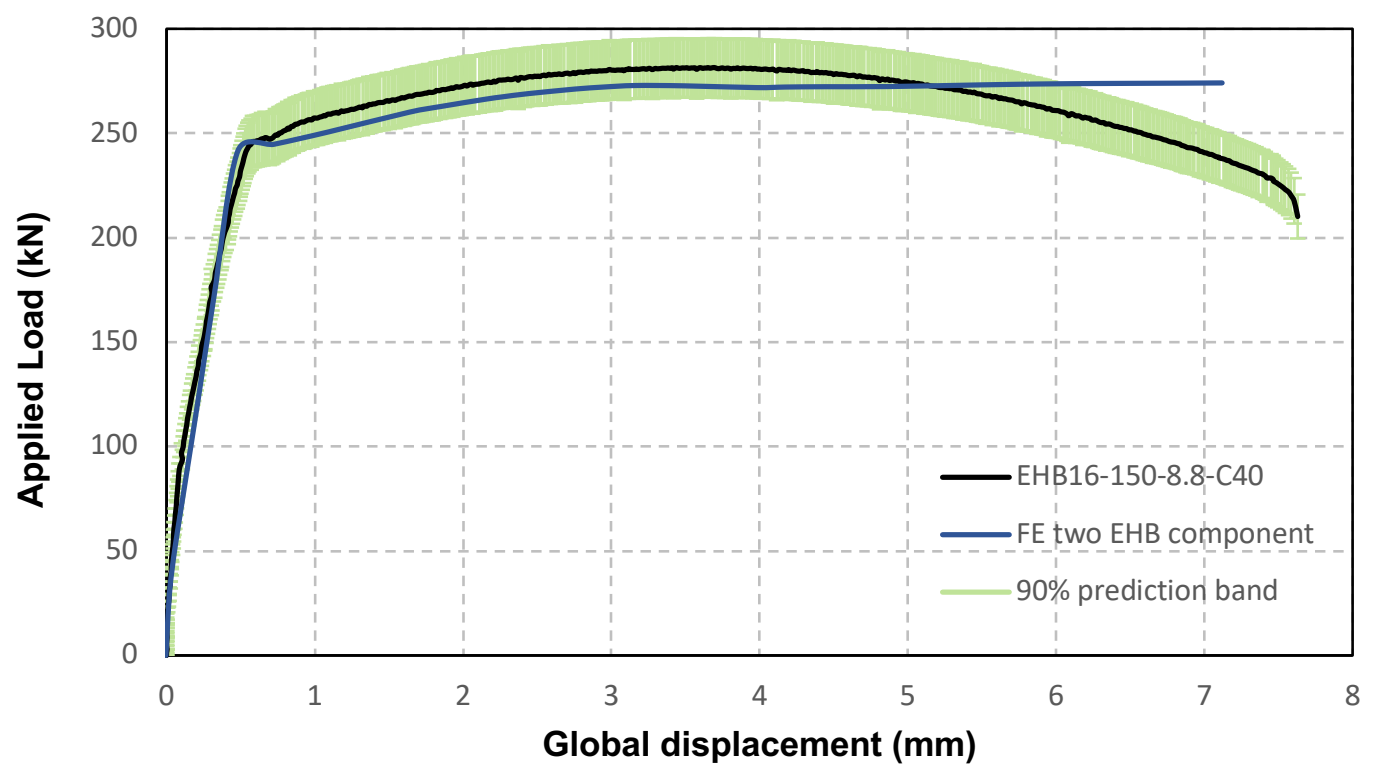

Fig. 9. Double EHB component load-displacement curve.

\subsubsection{General behaviour}

The column face deformation corresponds to the widening and forming the volcano shape around the bolt hole with the increase of the applied load, see Fig. 10. This is captured by the FE model as well as higher deformation in the interior half of the hole. This differential deformation is caused by the constraint imposed by the column wall.

The model captures the cone size at the concrete surface (1.4 times the bolts anchored length $L_{a n}$ ) for all concrete grades [26] and the outer perimeter of the crushing area (Fig. 11).

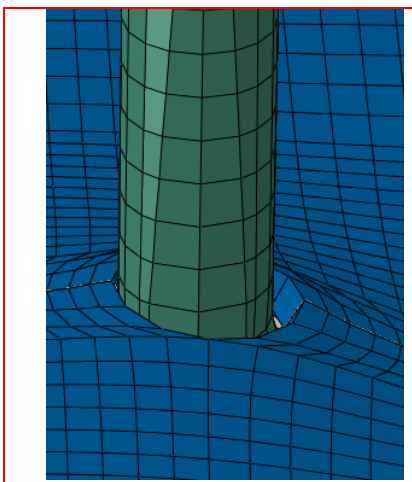

(a) FE analysis

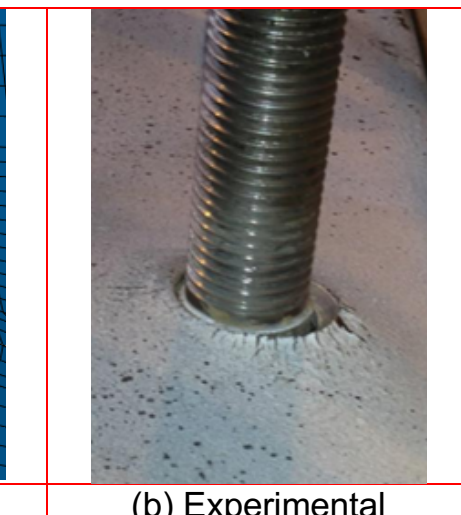

(b) Experimental
Fig. 10. Comparison between experimental and FE column face deformation.

\subsubsection{Force vs displacement curves}

The column component model is divided into two force intervals delimited by the change in stiffness (see
Table 2). Load vs displacement curves from experiments reported by Mahmood [26] and the FE results are presented in Fig. 12.

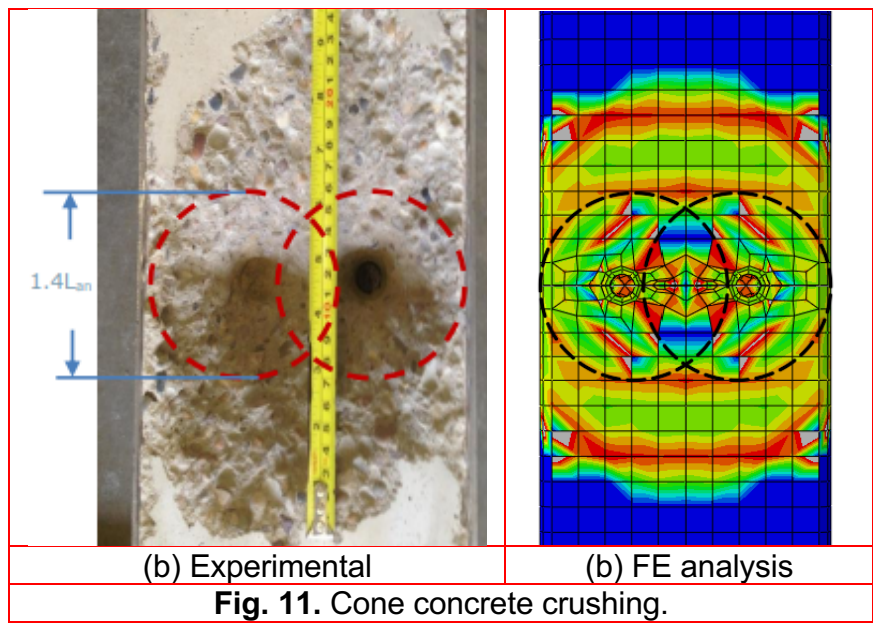

Table 2.

Numerical and experimental initial and second stiffness.

\begin{tabular}{ccccc}
\hline $\begin{array}{c}\text { Force } \\
\text { interval }\end{array}$ & Stiffness & $\begin{array}{c}\text { Exp. } \\
(\mathbf{k N} / \mathbf{m m})\end{array}$ & $\begin{array}{c}\text { Num. } \\
(\mathbf{k N / m m})\end{array}$ & $\begin{array}{c}\text { Error } \\
\mathbf{( \% )}\end{array}$ \\
\hline $0-0.23 \mathrm{~F}_{\mathrm{u}}$ & $\mathrm{k}_{1}$ & 970.71 & 929.80 & 4 \\
$0.23-0.9 \mathrm{~F}_{\mathrm{u}}$ & $\mathrm{k}_{2}$ & 385.60 & 332.07 & 16 \\
\hline
\end{tabular}

A peak is reached when the concrete failure occurs and after this point, the force drops to the column face strength and continue taking load according to the strength curve of the steel. Based on experimental 
observations, it was concluded that up to the plastic load of the column face component, the bolt/concrete

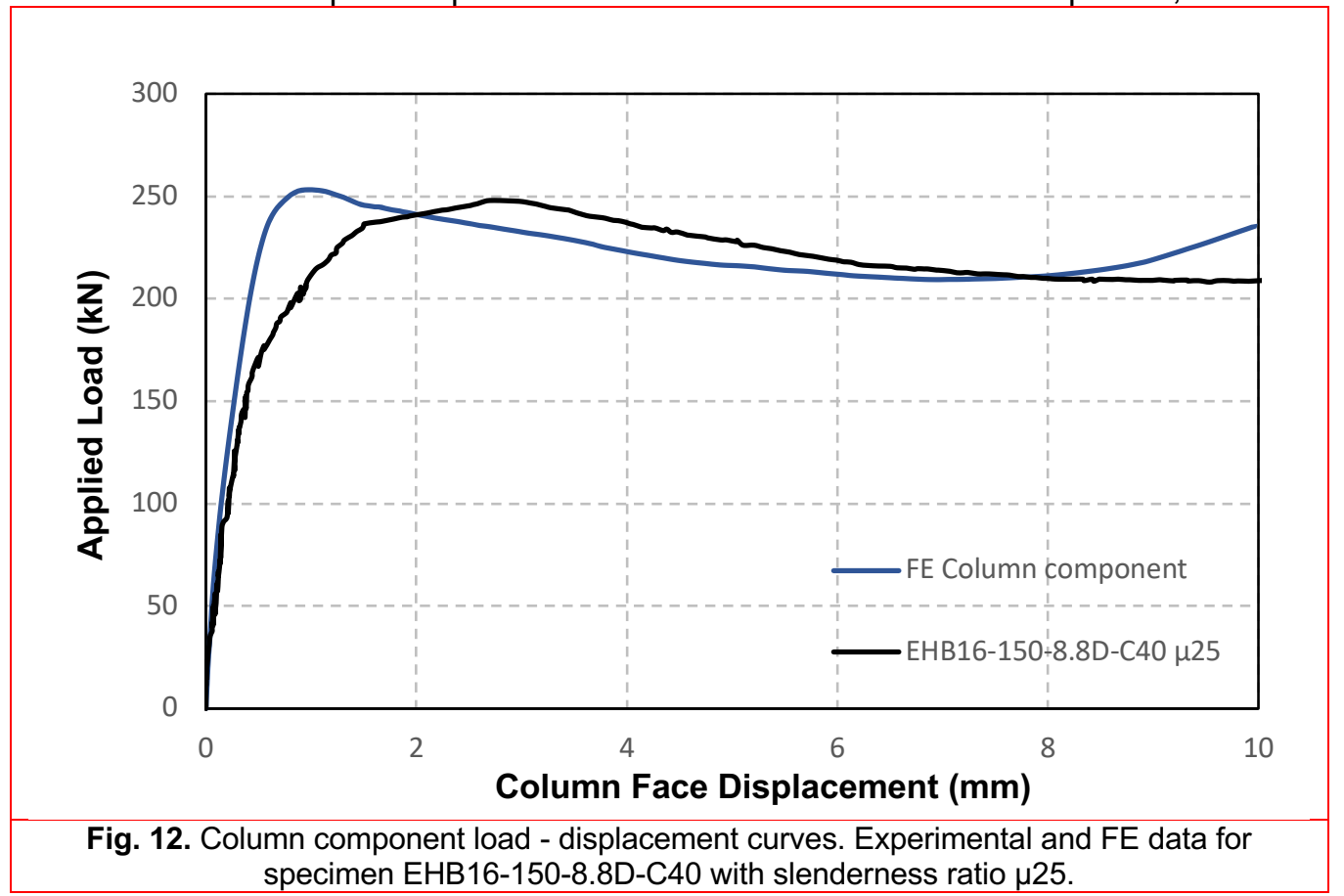

applied load with the column face plate. However, after the plastic strength is reached, the anchored contribution drops due to concrete crushing Mahmood [26].

Fig. 12 shows that the FE model captures the initial stiffness and the strength of the component well. However, there is a difference in capturing the upper stiffness. This is attributed to the difference in the geometry of the bolts used in each case. In the model, the exact geometry of the EHB was introduced while in the tests, dummy bolts were used. The general behaviour of the component is considered to be described well by the model.

\section{Combined failure numerical model results}

\subsection{Stress distribution from bolt pull-out}

The global displacement against the applied load is monitored in the combined FE model and plotted in Fig. 13Error! Reference source not found. to evaluate the general behaviour of the component. The pull-out force is transferred from the EHB to the surrounding concrete through the mechanical interlock between the bolt components (sleeves, bolt shank, threaded cone and anchor nut) and the concrete. The anchor nut distributes the stresses from the tensile load over a large region in the concrete infill. Hence, bolt shank, bolt hole, flaring sleeves and the concrete undergo continuous deformation.

The plastic load of the component $\left(F_{p}\right)$ is defined as the peak load $(244 \mathrm{kN})$ before the it starts falling. The load - displacement curve (Fig. 13) is divided into three sections. The first region goes from 0 to $0.2 F_{p}$ where all of the components behave in their elastic range. When the pull-out force reaches $20 \%$ of the plastic load, the first signs of concrete crushing around the anchored nut appear as the concrete yield stress is exceeded. The second region corresponds to load values from $0.2 F_{p}$ up to $0.64 F_{p}$, value at which the strain in the column face reaches its plastic value and stresses in the bolt increase greatly, almost reaching $90 \%$ of its ultimate tensile capacity at $F_{p}$. As the pull-out force is further increased above $F_{p}$, in the third region, the sleeves showed high concentration of stresses, exceeding the material ultimate strength which represents cracking of the sleeves and finally the bolt shank started necking when the bolt shank ultimate tensile capacity is reached.

The initial and the second stiffness of the component are influenced by the concrete compressive strength and column face behaviour. The concrete and steel reach their yield stress in the first region of the curve and exceed their ultimate strength before $F_{p}$. After this point, the stiffness of the component can be assumed to be fully dependent on the bolt and its components' properties.

The model shows a change in stiffness in the first region of the curve as it is presented in the bolt and column face components. The initial stiffness, between 0 and $0.2 F_{p}$, is followed by a decrease of stiffness up to $F_{p}$. The component initial and second stiffness are tabulated in Table 3. 


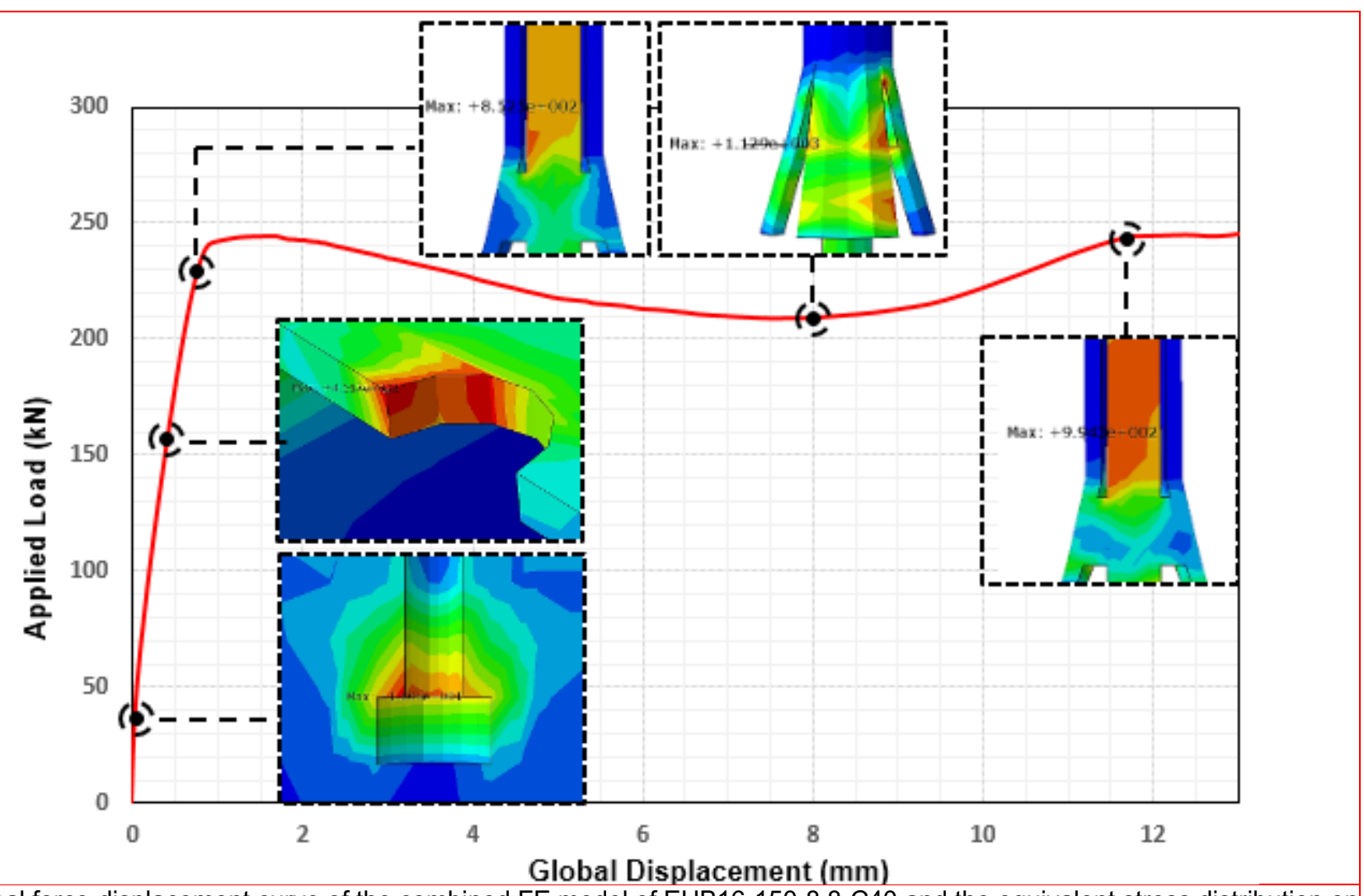

Fig. 13. Global force-displacement curve of the combined FE model of EHB16-150-8.8-C40 and the equivalent stress distribution on the bolt, concrete and column face.

Table 3.

Combined model numerical initial and second stiffness.

\begin{tabular}{ccc} 
Force interval & Stiffness & Numerical (kN/mm) \\
\hline $0-0.2 \mathrm{~F}_{\mathrm{p}}$ & $\mathrm{k}_{\mathrm{i}}$ & 977.50 \\
$0.2-1.0 \mathrm{~F}_{\mathrm{p}}$ & $\mathrm{k}_{\mathrm{s}}$ & 260.67 \\
\hline
\end{tabular}

\subsection{Parametric Study on Column Plate Thickness}

The thickness of the column face is defined in terms of its slenderness ratio $\mu$ which is the ratio of the column face width to its thickness (b/t). Three column thicknesses were used to investigate the effect of the slenderness ratio on the behaviour of the connection. The commercial thicknesses of $5,6.3$ and $8 \mathrm{~mm}$ correspond to $\mu$ of $40,31.75$ and 25 respectively. For all models, the bolt gauge distance $(80 \mathrm{~mm})$, the bolt anchorage length $(80 \mathrm{~mm})$ and the concrete grade $(\mathrm{C} 40)$ are used.

Column face slenderness ratio influences the stress distribution resulting from the EHB when subjected to a pull-out force. The stress distribution on the column face is presented in Fig. 14. There is formation of a volcano shape on the column top face with high stress concentration in the concrete crushing outer perimeter. Stresses are distributed in a bigger area in the column top face for $\mu 40$ with quick dissipation along the side faces and small influence on the column bottom face. For $\mu 25$, more even distribution of stresses is observed in all column faces and smaller affected area on the top face when compared to $\mu 40$. The distribution of stresses for slenderness ratio of 31.75 is in between the characteristics described for the thickest and thinnest columns.

The concrete failure around the anchor nut was monitored by identifying the load at which the concrete maximum strength is reached in the model. The relation between the load at which the concrete strength is exceeded $\left(F_{c u}\right)$ normalised by the plastic load $\left(F_{p}\right)$ for each model and the column face slenderness ratio is plotted in Fig. 15. 


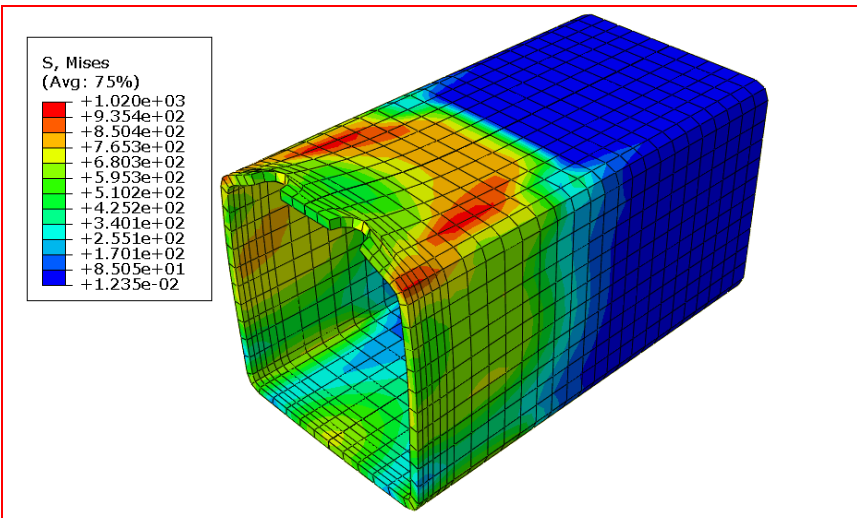

(a) $\mu 25$

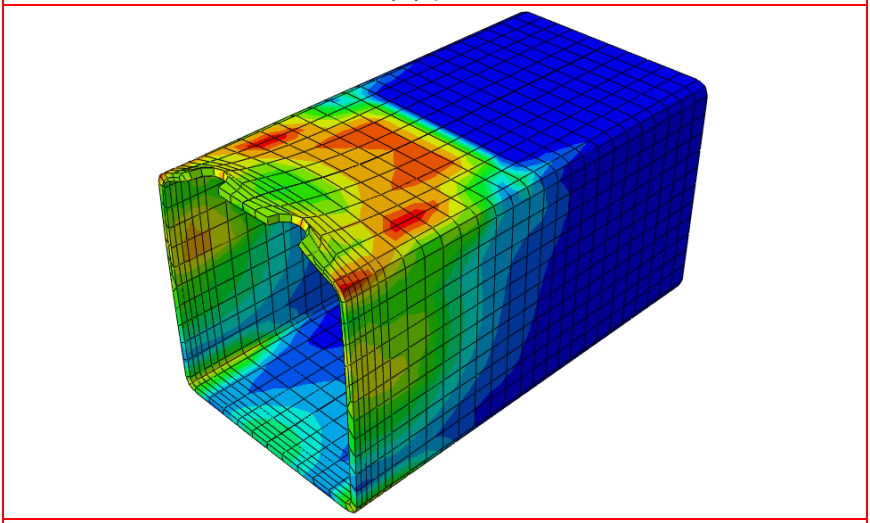

(b) $\mu 31.75$

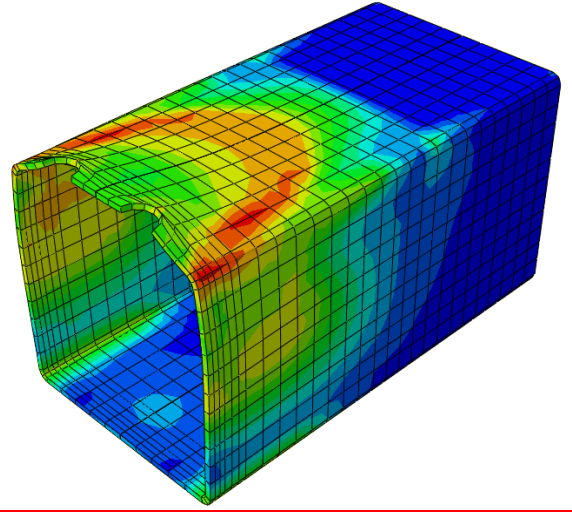

(c) $\mu 40$

Fig. 14. FE stress distribution for the hollow section at ultimate load.

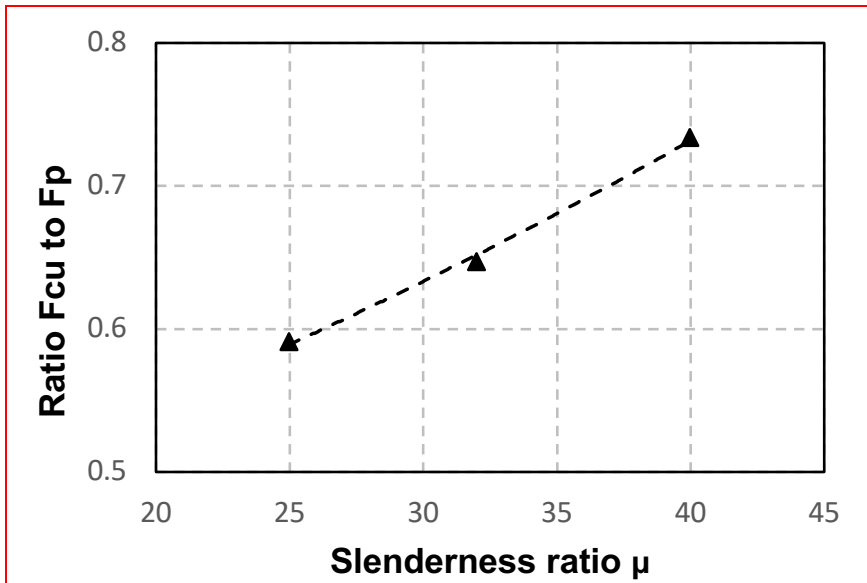

Fig. 15. Relation between the concrete ultimate strength load and slenderness ratio.

The concrete ultimate strength is reached at $60 \%$ of the plastic load for the model with $\mu$ equal to 25 . The percent increased to $65 \%$ for the model of 31.75 slenderness ratio and further increased to $73 \%$ in the $\mu 40$ model. The results suggest that there is a linear relationship between the load at which the concrete ultimate strength is exceeded and column face thickness, where thinner column thicknesses delay the concrete failure as both materials can deform more freely and there is less concentration of stresses in the concrete. Although concrete confinement does improve the concrete performance, this drop is mainly attributed to the drop in the plastic load, $F_{p}$, due to the higher slenderness rather than the concrete performance.

\subsection{Stiffness of the Extended Hollo-bolt}

The effect caused by varying the column thickness is displayed in Fig. 16. There is a similar trend pattern for the global force-displacement curves between all the slenderness ratios and a general increase in both initial and second stiffness when increasing the column thickness. The slenderness ratio has a clear effect on the component global displacement curve, all the FE models display a change in stiffness by an approximate tetralinear curve up to bolt failure. The component initial and second stiffness are reported in Table 4.

As reported by Mahmood et al. [15] for the column face component, the connection strength and stiffness are larger for thicker column sections. However, the amount of improvement in the component stiffness by changing $\mu$ from 40 to 31.75 is higher than that when varying it from 31.75 to 25 . This can be explained by the reduced contribution of the face bending stiffness compared with that contributed to by the concrete strength as the thickness decreases. 
Table 4.

EHB initial and second stiffness for various slenderness ratios.

\begin{tabular}{|c|c|c|}
\hline $\begin{array}{c}\text { Slenderness } \\
\text { ratio } \mu\end{array}$ & $\begin{array}{c}\text { Initial stiffness } \\
\mathrm{k}_{1},(\mathrm{kN} / \mathrm{mm})\end{array}$ & $\begin{array}{c}\text { Second stiffness } \\
k_{2},(k N / m m)\end{array}$ \\
\hline 25.00 & 977.50 & 260.67 \\
\hline $\begin{array}{l}31.75 \\
40.00\end{array}$ & $\begin{array}{l}908.73 \\
794.48\end{array}$ & $\begin{array}{l}249.73 \\
226.99\end{array}$ \\
\hline
\end{tabular}

\section{Analytical model}

The EHB connection behaviour in tension when combined failure can occur is dependent on many parameters such as bolt diameter, embedment depth, bolt gauge, concrete grade and column slenderness ratio. Spring model theory has been used by different authors to represent the connection behaviour.
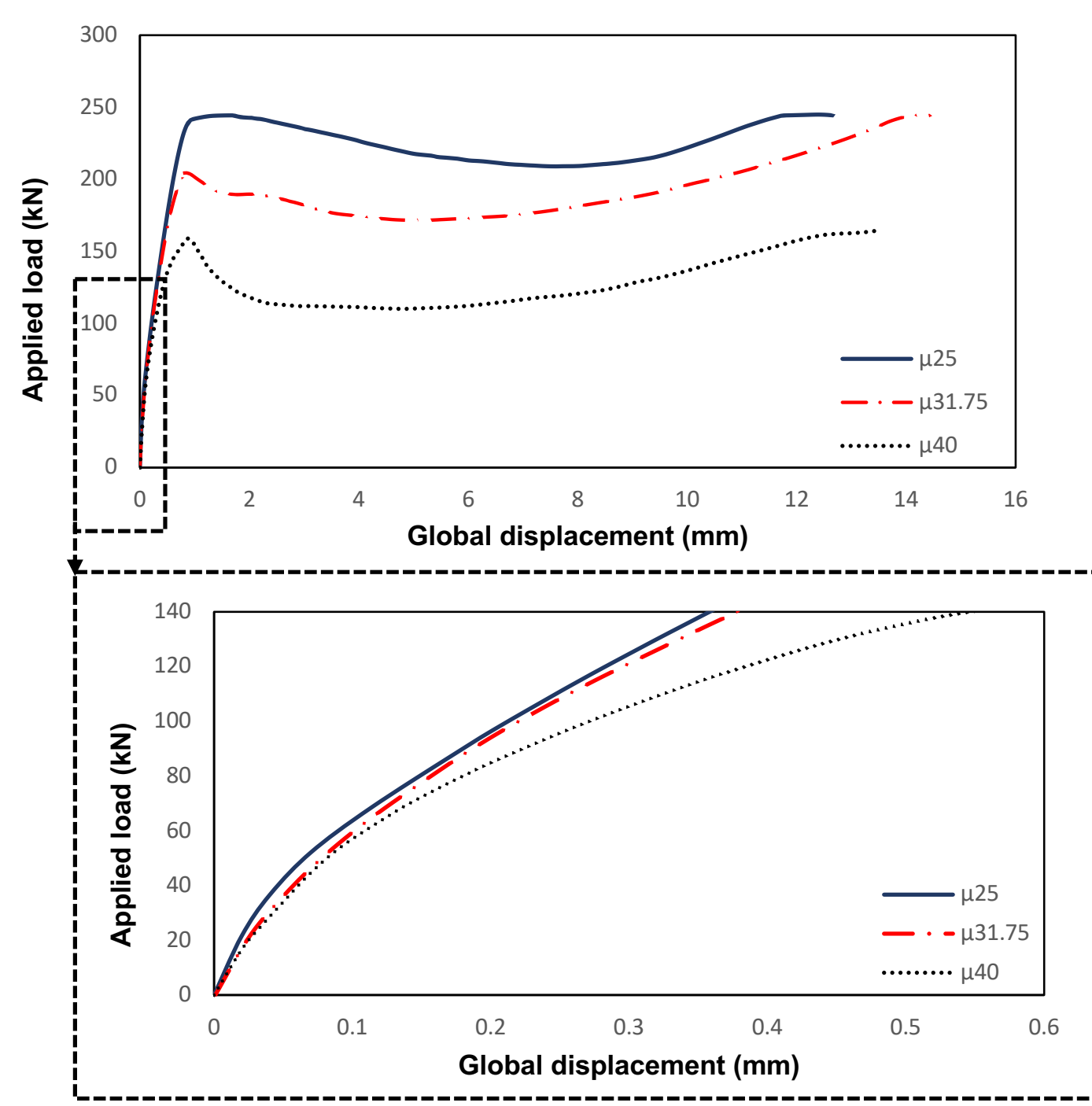

Fig. 16. Component behaviour for different slenderness ratio. 


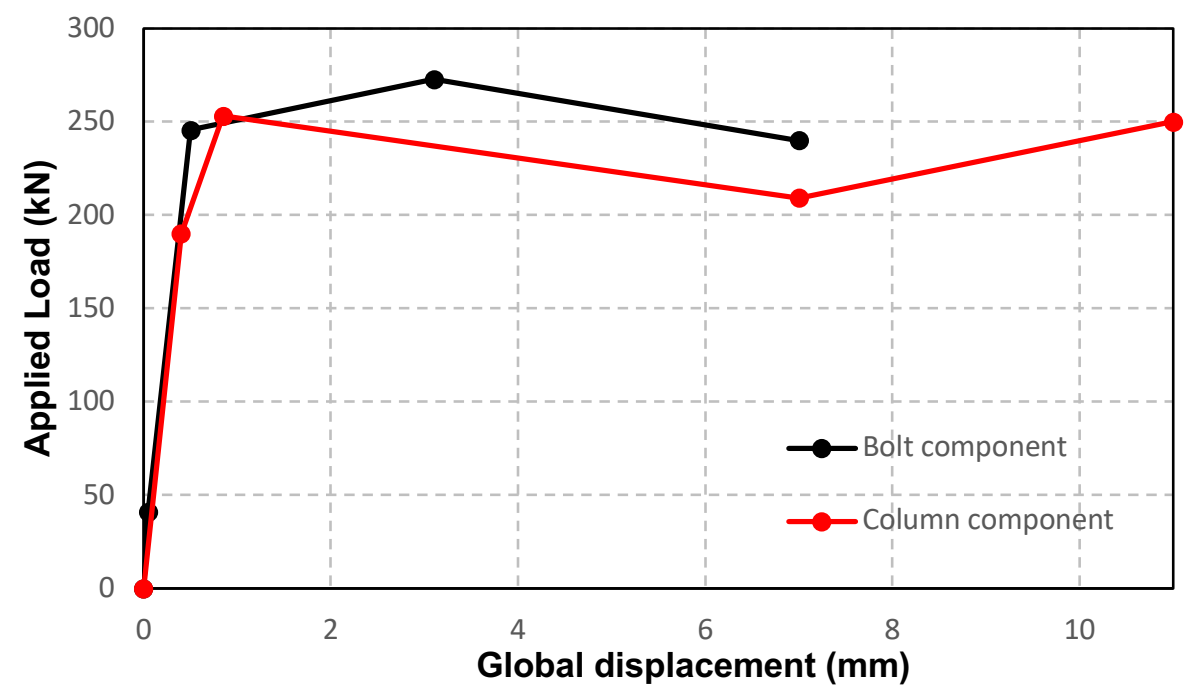

Fig. 17. Tetra-linear curves used to describe bolt and column components for $\mu 25$.

\subsection{Equivalent Spring Model}

The overall behaviour of the component in tension is approximated with the use of an equivalent massless spring model where the most important property is the stiffness of the spring. A helical spring methodology has been used independently to characterise the tensile behaviour of both bolt and column failure mechanisms of the EHB component. These models were found to provide reliable predictions and satisfy the componentbased approach for the design of the EHB connection.

The bolt component behaviour modelled by Pitrakkos [16] using the spring theory states that since the failure mode of the bolt component was due to bolt shank fracture, the ultimate strength was imposed as the ultimate strength of the internal bolt model. The column face component represented by Mahmood [26] states that the column face plastic load is equal to the resistance provided by the hollow section plate and the anchorage action.

The assembly of these spring models requires to define the arrangement of the springs based on observations of the FE pull-out behaviour. The non-linear behaviour of both components was approximated by tetra-linear curves using the results from the proposed FE models in the same way as Pitrakkos [16] and Mahmood [26], see Fig. 17. The pull-out of the bolt is produced near the plastic load of the combined component and therefore both components exhibit similar displacement level. After this point, the force levels are similar up to the bolt failure. Therefore, it is proposed a model with parallel spring configuration up to the plastic load and series arrangement from this point forward.

The following equations describe the resulting properties of the model assembly based on spring theory.
Parallel configuration

$$
\begin{aligned}
& F_{R d}=F_{R d 1}+F_{R d 2} \\
& k=k_{1}+k_{2} \\
& \delta_{C d}=\min \left(\delta_{1} ; \delta_{2}\right)
\end{aligned}
$$

Series configuration

$$
\begin{aligned}
& F_{R d}=\min \left(F_{R d 3} ; F_{R d 4}\right) \\
& k=\left(\frac{1}{k_{3}}+\frac{1}{k_{4}}\right)^{-1} \\
& \delta_{C d}=\delta_{3}+\delta_{4}
\end{aligned}
$$

Where $F_{R,} k$ and $\delta_{C d}$ are the force, stiffness and displacement levels as shown in Fig. 18.

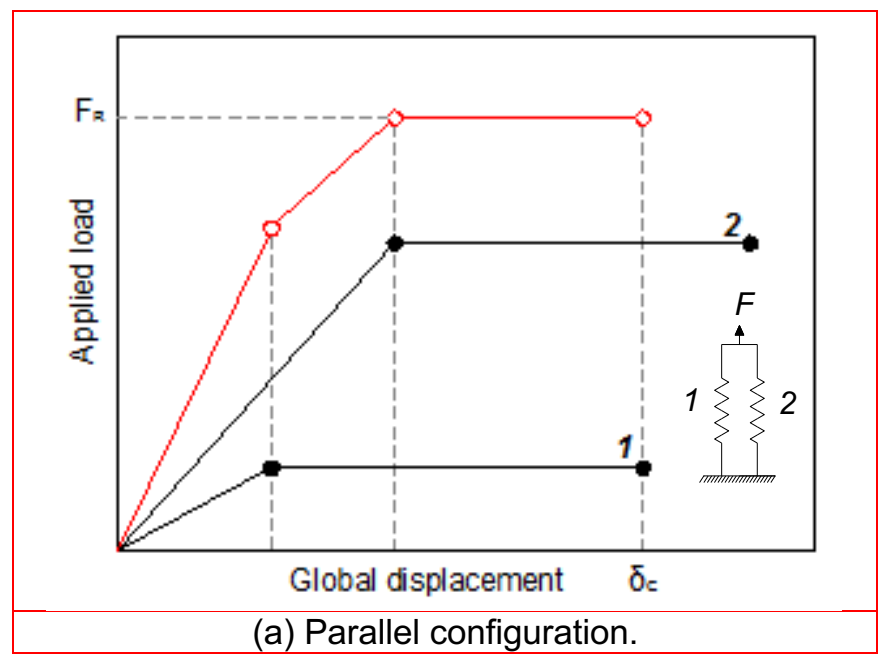


14

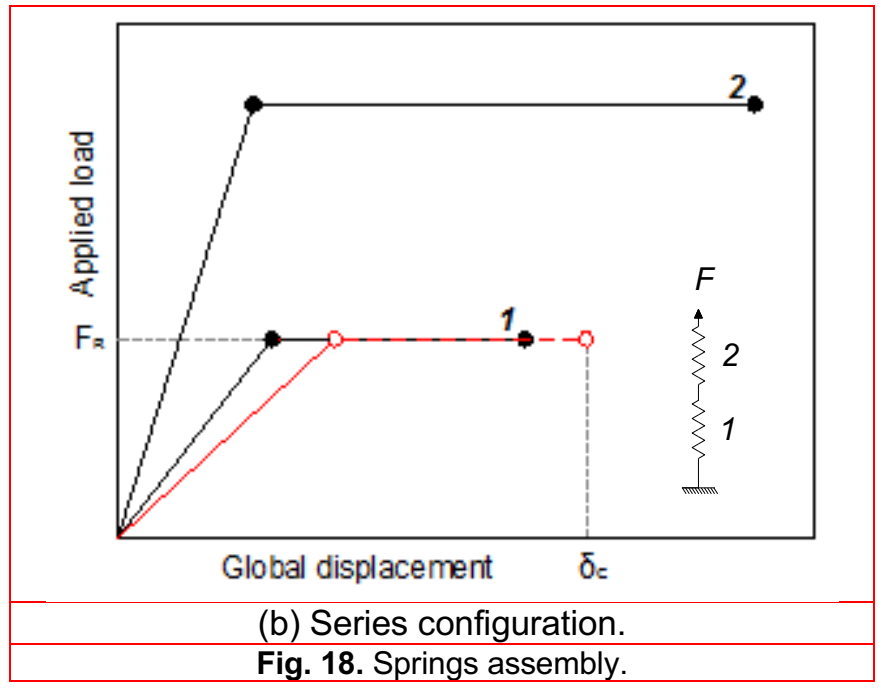

Using the spring theory for series configuration, the plastic load of the EHB combined component is calculated using Eq. 6 . The results are compared against the FE results in Table 5 for a single row of two 16EHB, $f_{y}=406 \mathrm{~N} / \mathrm{mm}^{2}, f_{c u}=40 \mathrm{~N} / \mathrm{mm}^{2}, b=200 \mathrm{~mm}, g=80 \mathrm{~mm}$ and $L_{a n}$ $=80 \mathrm{~mm}$ with variable slenderness ratio. The analytical model presents a good prediction to the component plastic load presenting a maximum error margin of $8 \%$.

Table 5. Plastic load analytical model validation.

\begin{tabular}{cccc}
\hline \multirow{2}{*}{$\begin{array}{c}\text { Slenderness } \\
\text { ratio } \boldsymbol{\mu}\end{array}$} & FE & Analytical & Difference \\
\cline { 2 - 4 } & 158.90 & 145.74 & $8 \%$ \\
40 & 204.46 & 195.59 & $4 \%$ \\
31.75 & 244.37 & 253.42 & $4 \%$ \\
25 & & &
\end{tabular}

\subsection{Overall Behaviour of the Component}

The combined failure component can be represented by a tetra-linear model similar to the one proposed by Mahmood [26] where the clear difference is observed in the first region of the curve. The model is composed by an initial stage between 0 and $20 \%$ of the plastic load; a secondary stage from the first stage up to $F_{p}$; a drop stage characterized by a decrease in the component resistance after the plastic load to the lowest load before the component strength starts picking up; and a final stage in which the component strength starts increasing again up to the bolt failure, see Fig. 19.

As described before, the slenderness ratio influences the initial stiffness of the connection. Therefore, the initial stiffness is derived from the linear relationship between the FE initial stiffness results and the column plate thickness described by Eq. 9:

$$
k_{i}=94.5 t+262.7
$$

The stiffness derived from the FE models for each stage of the proposed tetra-linear curve can be calculated using the following expressions:

$$
\begin{aligned}
k_{s} & =\frac{0.8 F_{p}}{\Delta_{p}-\Delta_{i}} \\
k_{d} & =\frac{F_{d}-F_{p}}{\Delta_{p}-\Delta_{d}} \\
k_{u} & =\frac{F_{u}-F_{p}}{\Delta_{u}-\Delta_{d}}
\end{aligned}
$$

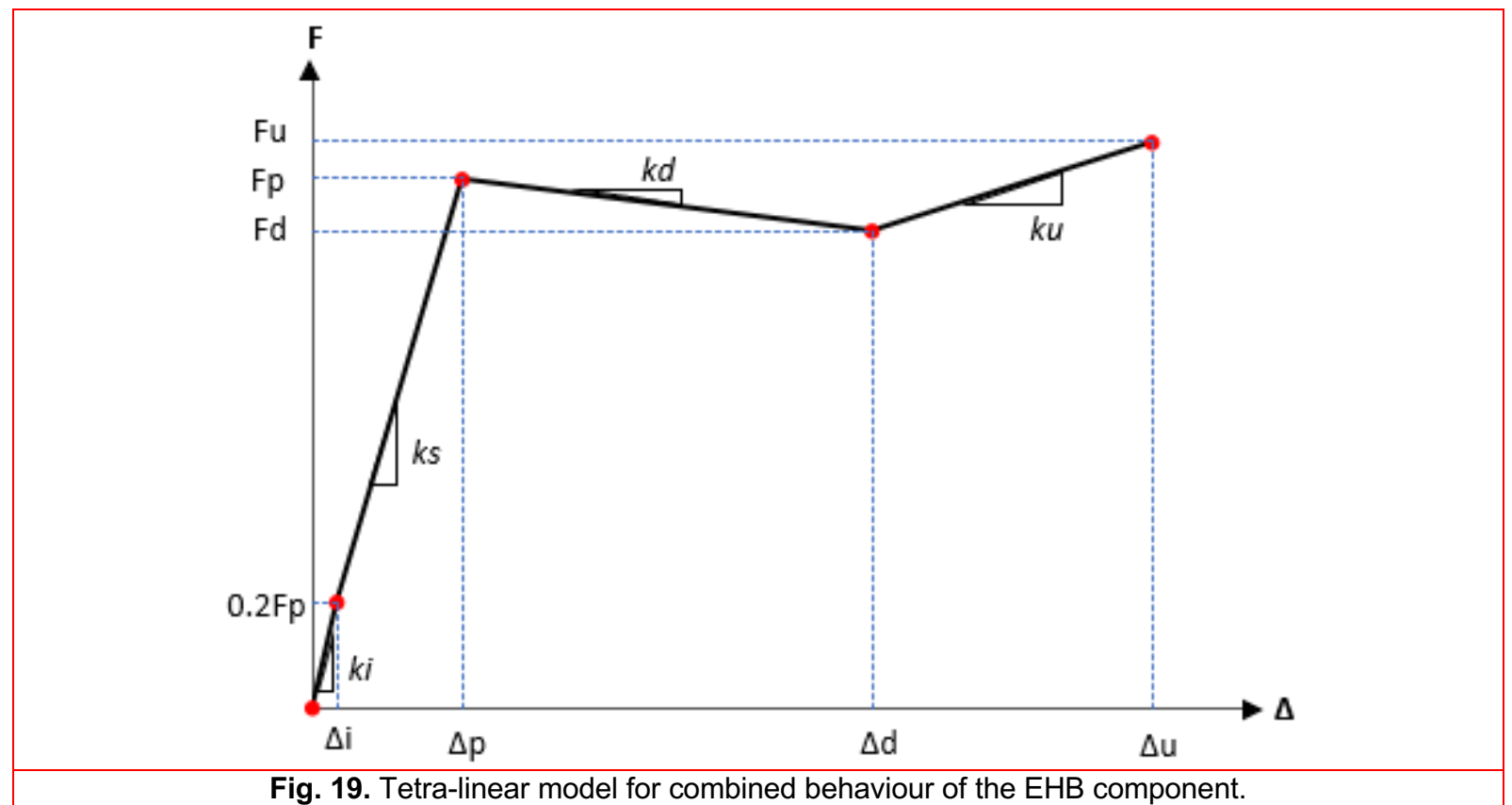

Fig. 19. Tetra-linear model for combined behaviour of the EHB component. 
The values of $k_{s}$ and $k_{u}$ are adopted as a percentage of the component initial stiffness as adopted by Ghobarah et al. [27] and Málaga-Chuquitaype \& Elghazouli [28] who expressed the post-yield stiffness as a percentage from the initial stiffness. Besides, the mean ratio between the drop displacement and the displacement at the plastic load is used to calculate the drop displacement. The following equations are proposed:

$$
\begin{aligned}
& k_{s}=0.276 k_{i} \\
& k_{u}=0.001 k_{i} \\
& \Delta_{d}=8.7 \Delta_{p}
\end{aligned}
$$

In order to calculate the drop stiffness $\left(k_{d}\right)$ using Eq. 11 , the value of the drop load $\left(F_{d}\right)$ must be known. Therefore, it is proposed a linear equation to calculate the drop load as a function of the plastic load $\left(F_{p}\right)$.

$$
F_{d}=1.1614 F_{p}-71.742
$$

The proposed tetra-linear global force-displacement curve for EHB16-150-8.8-C40 when varying the column plate thickness can be assembled by defining five points. The points are $\mathrm{P} 1(0,0), \mathrm{P} 2(0.20 \mathrm{Fp}, \Delta \mathrm{i}), \mathrm{P} 3(\mathrm{Fp}, \Delta \mathrm{p}), \mathrm{P} 4\left(\mathrm{~F}_{\mathrm{d}}\right.$, $\Delta d)$ and P5 $(F u, \Delta u)$. The displacement $\Delta i$ is defined using the following equations:

$$
\begin{aligned}
& \Delta_{i}=\frac{0.2 F p}{k_{i}} \\
& \Delta_{p}=\frac{F p}{0.276 k_{i}} \\
& \Delta_{u}=\frac{F u}{0.001 k_{i}}
\end{aligned}
$$

The proposed tetra-linear model results versus the numerical data are plotted in Fig. 20. Reasonable agreement between the models is observed within an error band of $15 \%$.

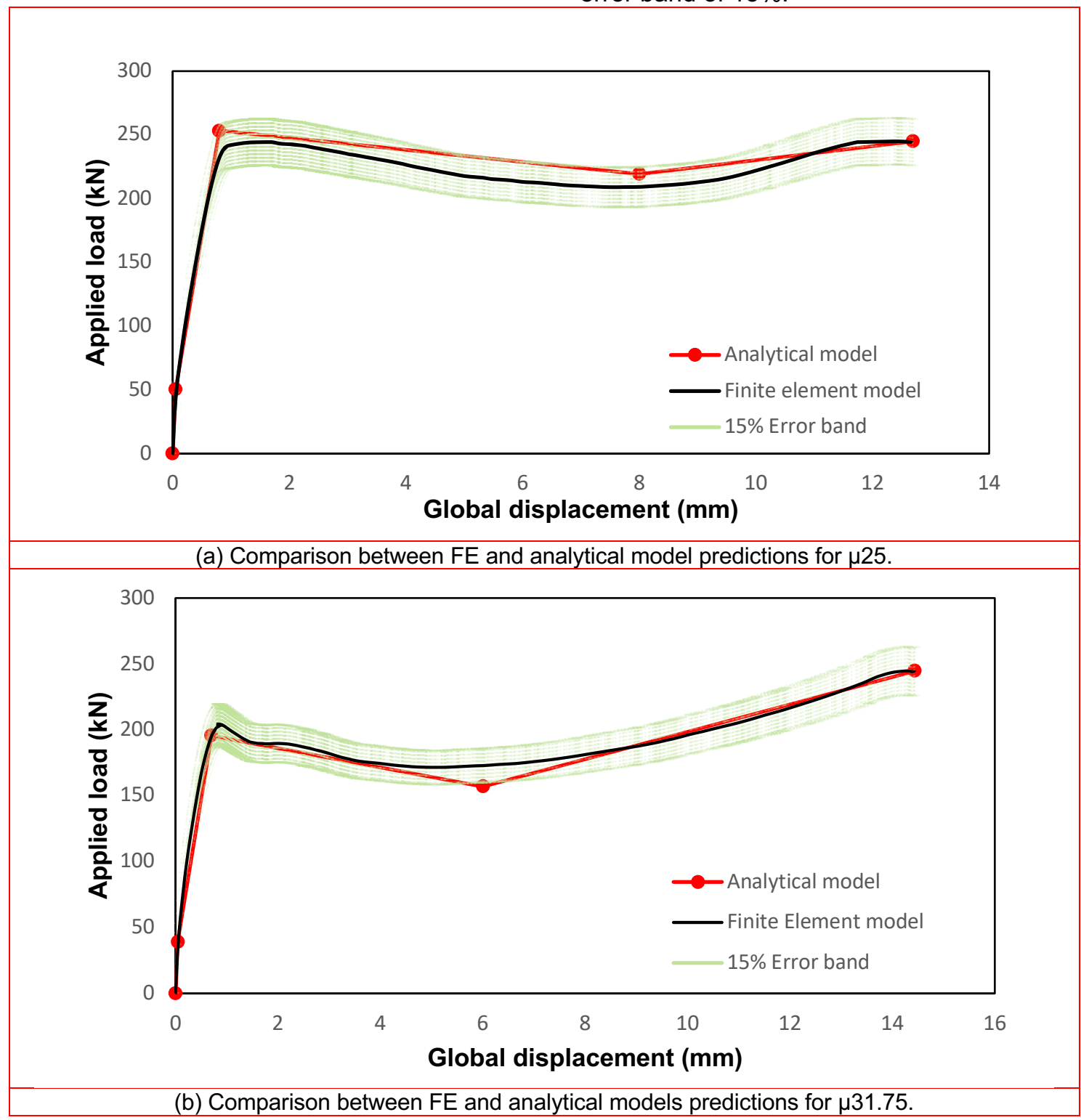




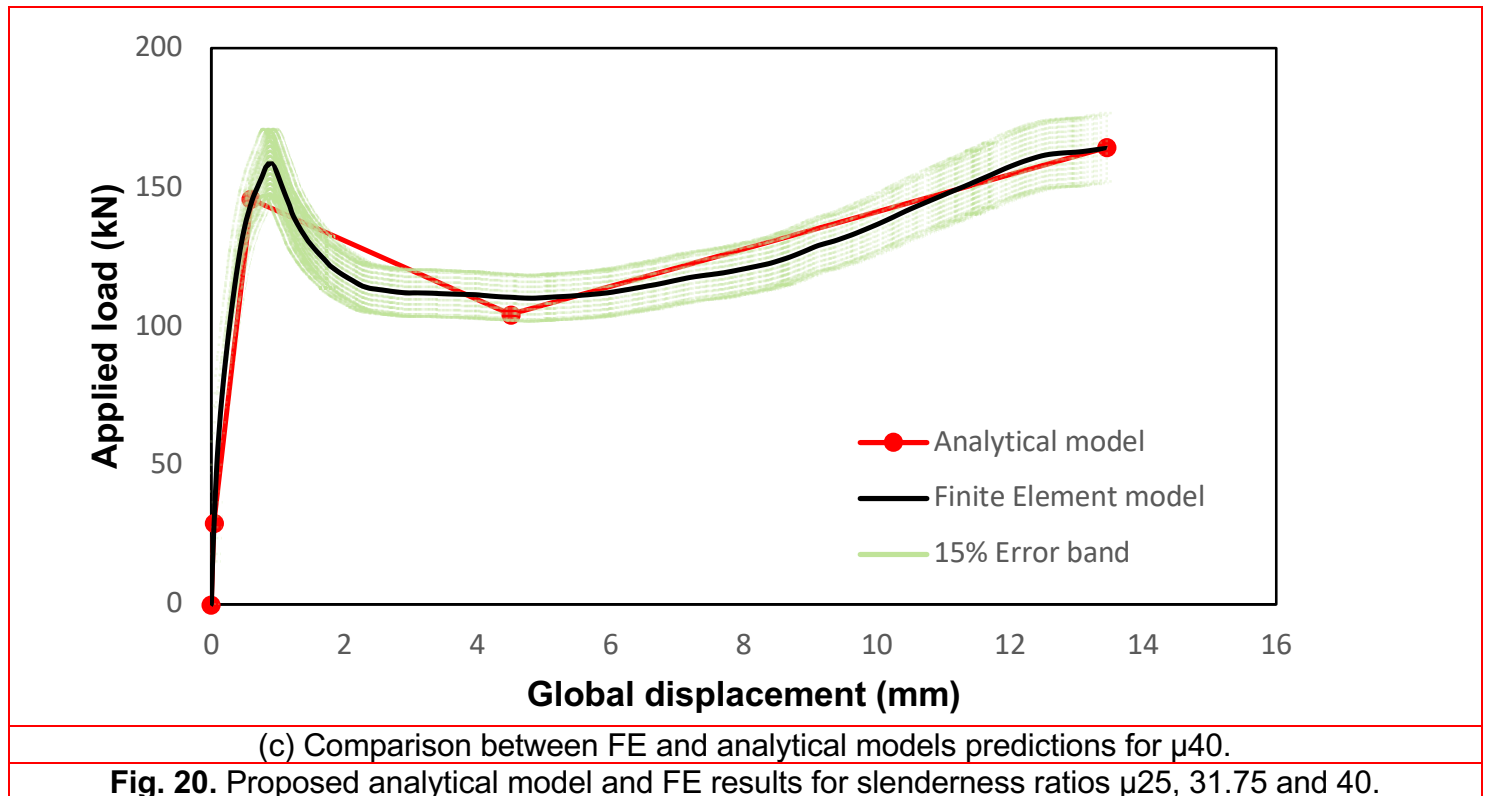

\section{Conclusion}

This paper presented the steps taken for the development of a validated finite element model that simulates the EHB component behaviour in tension when combined failure can occur and the effect of varying the column plate thickness on the connection behaviour. The model predicts the global force-displacement curve of the EHB connection when varying the steel column thickness or slenderness ratio with $90 \%$ accuracy. An analytical model was proposed. The model provides a good fit for the behaviour of the EHB component when compared with both the numerical analyses and the experimental data. Other findings of this work include:

- The first failure sign is caused by concrete crushing followed by hollow section yielding. After this, the component strength is dependent mainly on the bolt properties in tension (bolts necking and rupture).

- Components with larger slenderness ratio resists higher load before concrete failure. An optimal combination between concrete strength and column slenderness ratio requires further investigation.

- The general behaviour of the component can be represented by a tetra-linear model. The stiffness of each section is expressed as a percentage of the initial stiffness.

This work has provided an important step towards specifying an analytical model for this complex connection behaviour. Further research will be required to consider all the parameters influencing this combined component behaviour. A complete analytical model will allow the use of such connections in practice where designers are able to calculate strength and stiffness based on basic nominal design values for the concrete, hollow section and bolt.

\section{Acknowledgements}

The authors wish to acknowledge TATA Steel and Lindapter International, Bradford, for supporting this research.

\section{Funding}

This research did not receive any specific grant from funding agencies in the public, commercial, or not-forprofit sectors.

\section{References}

[1] Tao, Z., Uy, B., Han, L-H. \& Wang, Z-B. (2009) Analysis and design of concrete-filled stiffened thinwalled steel tubular columns under axial compression. Thin-Walled Structures, 47(12), pp.1544-1556. https://doi.org/10.1016/j.tws.2009. 05.006

[2] Uy, B., Tao, Z. \& Han, L.H. (2011) Behaviour of short and slender concrete-filled stainless steel tubular columns. Journal of Constructional Steel Research, 67(3), pp.360-378. https://doi.org/10.1016/j.jcsr. 2010.10.004

[3] Liu, Y., Chen, J., Zhang, X. \& Tan, D. (2018). Fatigue behaviour of blind bolts under tensile cyclic loads. Journal of Constructional Steel Research, 148, pp.16-27. https://doi.org/10.1016/j.jcsr.2018. $\underline{05.019}$

[4] Mirza, O. \& Uy, B. (2011) Behaviour of composite beam-column flush end-plate connections 
subjected to low-probability, high-consequence loading. Engineering Structures, 33(2), pp.647-662. https://doi.org/10.1016/j.engstruct.2010.05.024

[5] L. A. P. Silva, L.A.P., Neves, L. F. N. \& Gomes, F. C. T. (2003) Rotational Stiffness of Rectangular Hollow Sections Composite Joints. Journal of Structural Engineering, 129(4), pp.487-494. https://doi.org/10.1061/(ASCE)0733-9445(2003) 129:4(487)

[6] Pitrakkos, T. \& Tizani, W. (2013) Experimental behaviour of a novel anchored blind-bolt in tension. Engineering Structures, 49, pp.905-919. https://doi. org/10.1016/i.engstruct.2012.12.023

[7] Zeinizadeh Jeddi, M., Ramli Sulong, N.H. \& Arabnejad Khanouki, M.M., (2017). Seismic performance of a new through rib stiffener beam connection to concrete-filled steel tubular columns: An experimental study. Engineering Structures, 131, pp.477-491. https://doi.org/10.1016/j.engstruct. 2016.10.038

[8] Barnett, T., Tizani, W. \& Nethercot, D. (2001) The practice of blind bolting connections to structural hollow sections: A review. Steel and Composite Structures, $1(1), \quad$ pp.1-16. https://doi.org/10.1296/SCS2001.01.01.01

[9] Tizani, W. \& Ridley-Ellis, D. (2003) The performance of a new blind bolt for momentresisting connections. In: Jaurietta, M. A., Alonso, A. \& Chica, J. A., eds. Proceedings of the 10th international symposium on tubular structures, Balkema. 395-400.

[10] Agheshlui, H., Goldsworthy, H., Gad, E. \& Yao, H. (2016) Tensile Behavior of Groups of Anchored Blind Bolts within Concrete-Filled Steel Square Hollow Sections. Journal of Structural Engineering, 142(2), pp.1-18. https://doi.org/10.1061/(ASCE) ST.1943-541X.0001388

[11] Tizani, W., Wang, Z.Y. \& Hajirasouliha, I. (2013) Hysteretic performance of a new blind bolted connection to concrete filled columns under cyclic loading: An experimental investigation. Engineering Structures, 46, pp.535-546. https://doi.org/10. 1016/j.engstruct.2012.08.020

[12] Mahmood M., Tizani, W., \& Sansour, C. (2015) Effect of bolt gauge distance on the behaviour of anchored blind bolted connection to concrete filled tubular structures. In: Batista, Vellasco \& Lima, ed. Proceedings of the 15th International Symposium on Tubular Structures, Brazil. Taylor \& Francis Group, London. https://doi.org/10.1201/b18410-16

[13] Pitrakkos, T., \& Tizani, W. (2015) A component method model for blind-bolts with headed anchors in tension. Steel and Composite Structures, Vol. 18, No. $\quad 5, \quad 1305-1330$, http://dx.doi.org/10.12989/scs.2015.18.5.1305.

[14] Tizani W. \& Pitrakkos, T. (2015) Performance of TStub to CFT Joints Using Blind Bolts with Headed
Anchors. Journal of Structuctural Engineering, 141(10), pp. 1-11. https://doi.org/10.1061/ (ASCE)ST.1943-541X.0001169

[15] Mahmood, M., Tizani, W. \& Sansour, C., (2014). Effect of Tube Thickness on the Face Bending for Blind-Bolted Connection to Concrete Filled Tubular Structures. International Journal of Civil, Architectural, Structural and Construction Engineering, 8(9), pp.897-903.

[16] Pitrakkos, T. (2012) The Tensile Stiffness of a Novel Anchored Blind-bolt Component for Momentresisting Connections to Concrete-filled Hollow Sections, PhD thesis, Department of Civil Engineering, University of Nottingham, UK.

[17] Tizani, W., Rahman, N.A. \& Pitrakkos, T. (2014). Fatigue life of an anchored blind-bolt loaded in tension. Journal of Constructional Steel Research, 93, pp.1-8. https://doi.org/10.1016/.j.jcsr.2013.10. $\underline{002}$

[18] Elremaily, A. \& Azizinamini, A. (2001) Design provisions for connections between steel beams and concrete filled tube columns. Journal of Constructional Steel Research, 57(9), pp.971-995. https://doi.org/10.1016/S0143-974X(01)00016-5

[19] Hu, H-T., Huang, C-S., Wu, M-H. \& Wu, Y-M. (2003) Nonlinear Analysis of Axially Loaded ConcreteFilled Tube Columns with Confinement Effect. Journal of Structural Engineering, 129(10), pp.1322-1329. https://doi.org/10.1061/(ASCE) 0733-9445(2003)129:10(1322)

[20] Ellobody, E., Young, B. \& Lam, D. (2006) Behaviour of normal and high strength concrete-filled compact steel tube circular stub columns. Journal of Constructional Steel Research, 62(7), pp.706-715. https://doi.org/10.1016/j.jcsr.2005.11.002

[21] Wang, Z. (2012) Hysteretic response of an innovative blind bolted endplate connection to concrete filled tubular columns. $\mathrm{PhD}$ thesis, Department of Civil Engineering, University of Nottingham, UK.

[22] Genikomsou, A. S. \& Polak, M. A. (2015) Finite element analysis of punching shear of concrete slabs using damaged plasticity model in ABAQUS. Engineering Structures, 98, pp.38-48. https://doi.org/10.1016/S0143-974X(01)00016-5

[23] Abaqus, Inc. (2016) ABAQUS 6.14 Analysis User's Manual: Volume III: Material. Documentation, Dassault Systems.

[24] CEN, 2004. Eurocode 2: Design of concrete structures - Part 1-1: General rules and rules for buildings. British Standards Institution, 1(2004), p.230.

[25] Hillerborg, A. (1985) The theoretical basis of a method to determine the fracture energy GF of concrete. Materials and Structures, 18(4), pp.291296. https://doi.org/10.1016/S0143-974X(01)00016 $\underline{-5}$ 
[26] Mahmood, M.S. (2015) Column Face Bending of Anchored Blind Bolted Connections to Concrete Filled Tubular Sections, PhD thesis, Department of Civil Engineering, University of Nottingham, UK.

[27] Ghobarah, A, Mourad, S. \& Korol, R. M. (1996) Moment-Rotation Relationship of Blind Bolted Connections for HSS Columns. Journal of Constructional Steel Research, 40(1), pp.63-91. https://doi.org/10.1016/S0143-974X(96)00044-2

[28] Málaga-Chuquitaype, C. \& Elghazouli, A.Y. (2010) Component-based mechanical models for blindbolted angle connections. Engineering Structures, 32(10), pp.3048-3067. https://doi.org/10.1016/j. engstruct.2010.05.024 